\title{
Different screening definitions have little impact on polypectomy rate estimates
}

\author{
Mengzhu Jiang $\mathrm{MSc}^{1}$, Maida J Sewitch $\mathrm{PhD}^{1,2,3,4}$, Lawrence Joseph $\mathrm{PhD}^{1,3}$, Alan N Barkun MD MSc ${ }^{2,3,4}$
}

\begin{abstract}
M Jiang, MJ Sewitch, L Joseph, AN Barkun. Different screening definitions have little impact on polypectomy rate estimates. Can J Gastroenterol 2012;26(11):791-794.
\end{abstract}

BACKGROUND: Polypectomy rate is a surrogate quality indicator for screening colonoscopy. Various methods for identifying screening colonoscopies have been used and it is unclear how different definitions affect the estimated polypectomy rate.

OBJECTIVE: To estimate polypectomy rates and how they vary according to the definition of a screening colonoscopy, using patientand endoscopist-reported indications.

METHODS: A cross-sectional analysis of endoscopists and their patients 50 to 75 years of age who underwent colonoscopy was conducted. Based on questionnaire responses, four patient indications were derived: perceived screening; perceived nonscreening; medical history indicating nonscreening; and combination of the three indications. Endoscopist indication was derived from a questionnaire completed immediately after colonoscopy. Polypectomy status was obtained from provincial physician billing records. Polypectomy rates were computed, while accounting for physician and hospital level clustering, using all four patient indications, endoscopist indication, and the agreement between patient and endoscopist indications. The effect of indications on polypectomy rate was estimated adjusting for age, sex and family history of colorectal cancer.

RESULTS: A total of 2134 patients and 45 endoscopists were included. The proportion of colonoscopies classified as screening according to the nine indications ranged from $32.2 \%$ to $70.9 \%$. Polypectomy rates ranged between $22.6 \%$ and $26.2 \%$ for screening colonoscopy, and between $27.1 \%$ and $30.8 \%$ for nonscreening colonoscopy. Adjusted ORs for indication ranged between 0.74 and 0.94 .

DISCUSSION: Although the proportion of colonoscopies identified as screening varied considerably among the indications, the estimated polypectomy rates were similar.

CONCLUSION: The findings suggest that the way screening is defined does not greatly affect the estimates of polypectomy rate.

Key Words: Colonoscopy; Colorectal cancer screening; Indication; Polypectomy; Quality assurance

Colonoscopy is a crucial part of any colorectal cancer (CRC) screening strategy because it enables the identification and removal of precancerous and cancerous lesions throughout the entire colon. Recent CRC screening guidelines emphasize quality in colonoscopy (1). It is recommended that all endoscopists participate in quality assurance programs to ensure that they are operating within quality standards (2). Quality benchmarks for colonoscopy have been defined in terms of adenoma detection rate (ADR) in screening colonoscopies (3). It is important for researchers and administrators interested in colonoscopy quality to have reliable means of identifying screening colonoscopies.

Presently, it is difficult to identify colonoscopy indication in health administrative databases due to the lack of codes for screening,

\section{Le peu de répercussions de diverses définitions du dépistage sur les évaluations du taux de polypectomie}

HISTORIQUE : Le taux de polypectomie est un indicateur de qualité secondaire des coloscopies de dépistage. Il existe plusieurs méthodes pour déterminer les indications de coloscopie de dépistage, et on ne sait pas en quoi des définitions différentes influent sur le taux estimatif de polypectomie.

OBJECTIF : Évaluer le taux de polypectomie et sa variation d'après les définitions de coloscopie de dépistage, à l'aide des indications transmises par les patients et les endoscopistes.

MÉTHODOLOGIE : Les chercheurs ont effectué une analyse transversale des endoscopistes et de leurs patients de 50 à 75 ans qui ont subi une coloscopie. D'après les réponses à un questionnaire, ils ont dérivé quatre indications de patients : perception de lien avec le dépistage, perception d'absence de lien avec le dépistage, antécédents médicaux indiquant l'absence de lien avec le dépistage et association des trois indications. L'indication des endoscopistes était dérivée d'un questionnaire rempli immédiatement après la coloscopie. Les chercheurs ont obtenu le statut de polypectomie d'après les dossiers provinciaux de facturation des médecins. Ils ont calculé le taux de polypectomie tout en tenant compte du regroupement par médecin et par hôpital, à l'aide des quatre indications des patients, de l'indication des endoscopistes et de l'accord entre les indications des patients et celles de l'endoscopiste. Ils ont évalué l'effet des indications sur le taux de polypectomie compte tenu du rajustement selon l'âge, le sexe et les antécédents familiaux de cancer colorectal.

RÉSULTATS : Au total, 2134 patients et 45 endoscopistes ont été inclus dans l'étude. La proportion de coloscopies classées comme liées au dépistage d'après les neuf indications se situait entre $32,2 \%$ et 70,9\%. Le taux de polypectomie variait entre $22,6 \%$ et $26,2 \%$ à l'égard de la coloscopie de dépistage, et de $27,1 \%$ à 30,8 \% à l'égard des coloscopies non liées au dépistage. Le RRR des indications variait entre 0,74 et 0,94.

EXPOSÉ : Même si la proportion de coloscopies déterminées comme liées au dépistage varie considérablement entre les indications, le taux estimatif de polypectomie était similaire.

CONCLUSION : D'après ces résultats, la définition de dépistage n'influe pas tellement sur les évaluations du taux de polypectomie.

underuse and misuse of existing codes, under-reporting of indication and multiple indications for colonoscopy (4-6). In studies of the quality of screening colonoscopies, some investigators resorted to other methods of identifying screening procedures including referral physician indication $(7)$, patient-reported characteristics $(8,9)$ and medical chart review (10), while other investigators fell short of explicitly describing how screening was defined (11). We previously reported on the agreement among four different definitions of patient-perceived indication and endoscopist-reported indication (12); however, it is unclear how different ways of defining screening would affect ADRs and other quality measures.

The objective of the present study was to estimate polypectomy rates in screening and nonscreening colonoscopies as defined by

${ }^{1}$ Division of Clinical Epidemiology, Research Institute of the McGill University Health Centre, ${ }^{2}$ Department of Medicine, McGill University, ${ }^{3}$ Department of Epidemiology, Biostatistics and Occupational Health, McGill University, ${ }^{4}$ Division of Gastroenterology, McGill University Health Centre, Montreal, Quebec

Correspondence: Dr Maida J Sewitch, 687 Pine Avenue West, V Building, Room V2.15, Montreal, Quebec H3A 1A1.

Telephone 514-934-1934 ext 44736, fax 514-934-8293, e-mail maida.sewitch@mcgill.ca

Received for publication November 17, 2011. Accepted March 2, 2012 


\begin{tabular}{|c|c|}
\hline Indication & Definition of screening colonoscopy \\
\hline 1 & $\begin{array}{l}\text { Patient's perceived reason for their colonoscopy is any of } \\
\text { routine screening, family history or aging }\end{array}$ \\
\hline 2 & $\begin{array}{l}\text { Patient's perceived reason for their colonoscopy is not to } \\
\text { follow-up on a previous test or problem }\end{array}$ \\
\hline 3 & $\begin{array}{l}\text { No medical history indicating nonscreening (lower abdominal } \\
\text { symptoms in the past } 6 \text { months, history of colorectal cancer, } \\
\text { polyps, colon surgery, inflammatory bowel diseases or positive } \\
\text { fecal occult blood test in the past } 12 \text { months) }\end{array}$ \\
\hline 4 & Indications 1,2 , and 3 are screening \\
\hline 5 & Endoscopist-reported screening \\
\hline 6 & Indications 1 and 5 are screening \\
\hline 7 & Indications 2 and 5 are screening \\
\hline 8 & Indications 3 and 5 are screening \\
\hline 9 & Indications 4 and 5 are screening \\
\hline
\end{tabular}

different patient and endoscopist indications. Polypectomy rate is used in lieu of ADR because they have been shown to be highly correlated (correlation coefficient estimates of between 0.79 and 0.86) (13-15). For the purposes of both clinical research and quality assessment, it is important to know whether quality measures are sensitive to the way screening is defined.

\section{METHODS}

\section{Data collection}

The present cross-sectional analysis combined data from two previously assembled cohort studies. Patients were recruited between January and March 2007, and from January 2008 to March 2009 at seven hospitals in the Montreal (Quebec) area: Royal Victoria Hospital, Montreal General Hospital, St Mary's Hospital Centre, Jewish General Hospital, Hôpital Maisonneuve-Rosemont, Hôpital Fleury and Hôtel-Dieu. The study was approved by the McGill University Faculty of Medicine Institutional Review Board (Montreal, Quebec) and the research ethics boards at each study site.

Staff endoscopists at the hospitals were contacted for their consent to participate. To be eligible, the endoscopist was required to have Régie de l'assurance maladie du Québec (RAMQ) colonoscopy billing privileges. Immediately following the procedure, the endoscopist completed a questionnaire that had been attached to the participating patient's file. The questionnaire assessed the indication for colonoscopy (screening, follow-up, diagnostic, surveillance and other).

Consecutive patients who were scheduled for colonoscopy were recruited in the endoscopy waiting room. Inclusion criteria were as follows: 50 to 75 years of age; and scheduled for colonoscopy with a participating endoscopist. Exclusion criteria were as follows: patients not eligible for provincial health insurance coverage; patients without provincial health insurance coverage during the previous year; and those unable to provide informed consent. Eligible and consenting patients were administered a questionnaire that included items on perceived reason for colonoscopy, history of gastrointestinal (GI) conditions, lower abdominal symptoms, previous CRC screening tests and family history of CRC. Patients were asked to provide their health insurance card numbers to facilitate data linkage with RAMQ physician billing records. Extracted from the RAMQ database were data regarding patient age group and sex, and all medical procedures performed on the date of, and up to 30 days after the index colonoscopy. Patient polypectomy status was determined from the presence of the polypectomy billing code on the date of the colonoscopy or within two days after colonoscopy. Polypectomy status obtained from physician billing claims databases is reasonably accurate (16).
Definitions of colonoscopy indication

Patient indication was classified in four ways (Table 1) (12). Endoscopist-reported indication (indication 5) was derived from the endoscopist questionnaire. Indications 6 to 9 were based on the agreement between endoscopist indication and patient indications 1 to 4 , respectively. For indications 6 to 9, a colonoscopy was considered to be screening only if it was screening by both patient and endoscopist indications, while nonscreening colonoscopies required both patient and endoscopist to suggest nonscreening.

\section{Statistical analyses}

Polypectomy rates were estimated using Bayesian hierarchical logistic regression models with random intercepts to account for physician level clustering. All modelling was conducted using WinBUGS version 1.4.3 (WinBUGS, United Kingdom). Estimated polypectomy rates were adjusted to account for the imperfect accuracy of polypectomy reporting in RAMQ physician billing records. Sensitivity and specificity of RAMQ polypectomy code relative to medical chart review has been previously estimated to be $84.7 \%$ (95\% CI $78.6 \%$ to $89.4 \%$ ) and $99.0 \%$ (95\% CI $97.5 \%$ to $99.6 \%$ ), respectively (16). The uncertainties of these estimates were taken into account in the present study by converting the Cls into close-fitting beta densities, which were used in the model as prior distributions for sensitivity and specificity, respectively. Diffuse (noninformative) prior distributions were used for all other parameters. To estimate the effect of each of the indications on polypectomy status, age (ordinal: 50 to 54,55 to 59,60 to 64, 65 to 70 and 70 to 75 years), sex and family history of CRC were entered into the hierarchical models. Bayesian 95\% credible intervals are reported for all model results.

\section{Recruitment statistics}

\section{RESULTS}

Forty-eight endoscopists consented to study participation, but three were later found to not have RAMQ billing rights and were excluded from further analyses. The remaining 45 physicians were comprised of $38(84 \%)$ gastroenterologists, six (13\%) surgeons and one (2\%) internist. Of the 2614 patients who were approached, 162 (6\%) were ineligible and 236 (9\%) of eligible patients declined participation. Of the remaining 2216 (84\%) who consented to participate, 82 (4\%) were excluded for the following reasons: colonoscopy was performed by a physician without RAMQ billing rights $(n=45)$; individual protocol violation (colonoscopy performed by nonparticipating physicians, noncompletion of colonoscopy, wrong questionnaire used) ( $\mathrm{n}=12$ ); health care card number not found in RAMQ ( $n=12)$; consent withdrawn $(n=1)$; patients sampled more than once $(n=5)$; and key questionnaire items missing for patient indication $(n=7)$. In total, data from 2134 (82\%) unique patients who underwent colonoscopy were included.

\section{Patient characteristics}

Key patient characteristics are summarized in Table 2. The mean age was 62 years and $50 \%$ of the participants were female. Of all patients, $29.4 \%$ reported a history of GI conditions, $40.0 \%$ experienced lower abdominal symptoms in the previous six months, $23.7 \%$ reported a family history of CRC, $2.8 \%$ had a positive fecal occult blood test in the past 12 months and $46.4 \%$ reported having undergone a colonoscopy in the past 10 years.

\section{Proportion of colonoscopies according to indication}

The proportions of colonoscopies classified as screening ranged from $32.2 \%$ to $70.9 \%$ (Table 3 ). Considering indications 1 to 4 , progressively fewer colonoscopies were classified as screening. As expected, indications 6 to 9 identified fewer screening procedures compared with indications 1 to 4 because the criteria were more stringent. The endoscopist indication (indication 5) classified $55.1 \%$ of colonoscopies as screening. 
TABLE 2

Patient characteristics $(n=2134)$

\begin{tabular}{lc}
\hline Characteristic & $61 \pm 7$ \\
\hline Age, years, mean \pm SD & $1070(50.1)$ \\
Male sex & $627(29.4)$ \\
History of gastrointestinal conditions & $67(3.1)$ \\
Ulcerative colitis & $38(1.8)$ \\
Crohn disease & $480(22.7)$ \\
Colon polyps & $78(3.7)$ \\
Colon cancer & $131(6.1)$ \\
Colon/bowel surgery & $853(40.0)$ \\
Lower abdominal symptoms in past six months & $429(20.1)$ \\
Rectal bleeding & $109(5.1)$ \\
Unintentional weight loss & $391(18.3)$ \\
Change in bowel habits & $344(16.1)$ \\
Lower abdominal pain & $227(10.7)$ \\
Anemia in past 12 months & $60(2.8)$ \\
Positive FOBT in the past 12 months & $991(46.4)$ \\
Colonoscopy in the past 10 years & $505(23.7)$ \\
Family history of colon cancer &
\end{tabular}

Data presented as $n$ (\%) unless otherwise indicated. FOBT Fecal occult blood test

\section{TABLE 3}

\section{Proportions of colonoscopies identified as screening} according to indication

\begin{tabular}{lc}
\hline Indication & $\%(95 \% \mathrm{CI})$ \\
\hline 1 & $70.9(69.0-72.9)$ \\
2 & $53.7(51.6-55.8)$ \\
3 & $40.3(38.2-42.4)$ \\
4 & $35.5(33.4-37.5)$ \\
5 & $55.1(52.9-57.2)$ \\
6 & $49.2(47.0-51.3)$ \\
7 & $41.9(39.8-44.1)$ \\
8 & $35.2(33.1-37.2)$ \\
9 & $32.2(30.2-34.2)$ \\
\hline
\end{tabular}

Indications were defined as follows: 1 Patient-perceived screening; 2 Patientperceived nonscreening; 3 Patient-reported medical history and gastrointestinal symptoms; 4 Combination of indications 1 to 3; 5 Endoscopist-reported screening; and 6 to 9 Combinations of 5 with 1 to 4 , respectively

\section{Polypectomy rates according to indication}

The overall polypectomy rate before adjustment to account for the accuracy of the RAMQ database was $22.7 \%$ (95\% CI 18.2 to 27.4). Among the different indications, the unadjusted rates ranged from $20 \%$ (indication 6) to $22.9 \%$ (indication 2) for screening, and from $23.7 \%$ (indication 2) to $26.8 \%$ (indication 5) for nonscreening colonoscopies. Adjustment consistently increased the polypectomy rate estimates by $2 \%$ to $4 \%$. The adjusted rate estimates ranged from $22.6 \%$ to $26.2 \%$ for screening and $27.1 \%$ to $30.8 \%$ for nonscreening colonoscopy (Table 4). The median adjusted estimates among the nine indications were $24.2 \%$ (indication 8 ) for screening and $29.9 \%$ (indication 6) for nonscreening colonoscopies.

Effect of indication on polypectomy

To estimate the effect of indication on polypectomy status, logistic regression was performed for each indication with age, sex and family history of CRC as covariates. Adjustment for covariates did not greatly affect OR estimates compared with univariate models (Table 5). Adjusted ORs for indication ranged from 0.74 to 0.94 .

\section{DISCUSSION}

We estimated polypectomy rates using nine indications that identified screening and nonscreening colonoscopies based on patient and endoscopist reports. There was considerable variability in the
TABLE 4

Adjusted polypectomy rates in screening and nonscreening colonoscopies based on the nine indications*

\begin{tabular}{lcc}
\hline & \multicolumn{2}{c}{ Polypectomy rate, \% (95\% Cl) } \\
\cline { 2 - 3 } Indication $^{\dagger}$ & Screening colonoscopies & Nonscreening colonoscopies \\
\hline 1 & $25.5(20.1-31.5)$ & $28.3(20.8-36.1)$ \\
2 & $26.2(20.5-32.2)$ & $27.1(20.8-33.9)$ \\
3 & $25.7(19.8-32.1)$ & $27.5(21.5-33.9)$ \\
4 & $25.2(19.0-31.6)$ & $27.5(21.5-33.6)$ \\
5 & $23.1(17.2-29.3)$ & $30.8(24.3-37.6)$ \\
6 & $22.6(17.0-29.1)$ & $29.9(22.2-37.6)$ \\
7 & $24.0(18.0-30.4)$ & $30.4(23.2-37.7)$ \\
8 & $24.2(18.2-30.6)$ & $30.2(23.3-37.4)$ \\
9 & $24.1(17.9-30.8)$ & $30.5(23.8-37.4)$ \\
\hline
\end{tabular}

*Adjusted for the sensitivity and specificity of the physician billing claims database for polypectomy status; ${ }^{\dagger}$ Indications were defined as follows: 1 Patientperceived screening; 2 Patient-perceived nonscreening; 3 Patient-reported medical history and gastrointestinal symptoms; 4 Combination of indications 1 to 3; 5 Endoscopist-reported screening; and 6 to 9 Combinations of 5 with 1 to 4 , respectively

\section{TABLE 5}

ORs for the nine indications as a predictor of polypectomy status

\begin{tabular}{lcc}
\hline $\begin{array}{l}\text { Indication* } \\
\text { (screening relative to }\end{array}$ & \multicolumn{2}{c}{ OR (95\% Cl) } \\
\cline { 2 - 3 } nonscreening) & Unadjusted & Adjusted $^{\dagger}$ \\
\hline 1 & $0.88(0.70-1.10)$ & $0.89(0.70-1.13)$ \\
2 & $0.94(0.76-1.15)$ & $0.92(0.74-1.14)$ \\
3 & $0.91(0.74-1.13)$ & $0.94(0.76-1.18)$ \\
4 & $0.88(0.70-1.10)$ & $0.90(0.72-1.12)$ \\
5 & $0.72(0.59-0.89)$ & $0.75(0.60-0.92)$ \\
6 & $0.72(0.58-0.88)$ & $0.74(0.59-0.91)$ \\
7 & $0.82(0.67-1.02)$ & $0.83(0.67-1.04)$ \\
8 & $0.84(0.67-1.04)$ & $0.86(0.69-1.08)$ \\
9 & $0.84(0.67-1.04)$ & $0.86(0.68-1.08)$ \\
\hline
\end{tabular}

*Indications were defined as follows: 1 Patient-perceived screening; 2 Patientperceived nonscreening; 3 Patient-reported medical history and gastrointestinal symptoms; 4 Combination of indications 1 to 3; 5 Endoscopist-reported screening; and 6 to 9 Combinations of 5 with 1 to 4 respectively; ${ }^{\dagger}$ Adjusted for patient age, sex and family history of colorectal cancer

proportion of colonoscopies defined as screening according to indication. Indication 1 (perceived screening) was the most relaxed criterion, while indication 2 (perceived nonscreening) and indication 3 (GI history) were more stringent. Indication 3 is most consistent with the guidelines in which screening is defined as procedures in asymptomatic average-risk individuals (3). Several recent studies on screening colonoscopy have based their inclusion and exclusion criteria on patient-reported history of GI conditions and symptoms $(9,17,18)$. Indication 4 (combination of 1 to 3 ) was the most strict of all patient criteria. Indications 6 to 9 were more restrictive than their counterparts in 1 to 4 because they required both patient and endoscopist to agree on screening. The trend observed was consistent with the restrictiveness of the indications, with less stringent indications identifying more screening procedures compared with those that were more stringent. Despite the variation in the number of screening colonoscopies, the indications yielded very similar polypectomy rates for both screening and nonscreening colonoscopies. This may be due to the fact that the rates for screening and nonscreening were comparable. Adjusted polypectomy rates ranged between $22.6 \%$ and $26.2 \%$ for screening colonoscopy, and between $27.1 \%$ and $30.8 \%$ for nonscreening. Adjustment for the imperfect accuracy of the polypectomy procedure code raised the polypectomy rates by $3 \%$ to $5 \%$. For quality assurance within the province, adjustment may not be necessary. However, because 
provincial databases will have different accuracies for polypectomy reporting, adjustment is necessary to make results interpretable and comparable across provinces.

From the multivariate models, most ORs for indication as a predictor of polypectomy status were not significant with the exception of indications 5 and 6 . Based on the point estimates, the endoscopist and agreement-based indications appear to be better predictors compared with patient indications. However, due to multiple testing and wide Cls around the point estimates, there is insufficient evidence to conclude that these indications are clinically relevant predictors of polypectomy status. Previous studies have reported that indication for colonoscopy is not an important predictor of $\operatorname{ADR}(19,20)$. Therefore, the shifting of some colonoscopies between screening and nonscreening groups according to indication may not have substantially affected the polypectomy rate estimates. However, it is worth noting that the less restrictive indications ( 1 to 4 ) yielded slightly higher estimates for screening and lower rates for nonscreening compared with more restrictive indications, likely by including some nonscreening colonoscopies as screening.

Limitations of our findings include information bias and generalizability issues. All but one of our study sites were tertiary care centres in Montreal, and the findings may not be generalizable to smaller practices or rural settings. The endoscopist indication and the indications derived from it may be subject to reporting bias because the indication was assessed postprocedure when the outcome (polypectomy) was already known to the endoscopist. Also, $46.4 \%$ of participants reported having undergone a colonoscopy in the past 10 years. There is growing consensus that previously screened patients are expected to have lower polypectomy rates and ADRs, and that quality benchmarks should apply only to first-time screenees (21). We did not exclude previously screened patients from our analyses because the objective was to compare how indications for screening perform relative to one another, rather than to assess whether benchmarks were met.

The extent to which our conclusions can be extended to ADR relies on the correlation between polypectomy rate and ADR. Studies suggesting that the correlation is high are based on a small number of endoscopists (13-15). This correlation may or may not hold true for endoscopists in our study and cannot be verified from the data we

\section{REFERENCES}

1. Rex DK, Johnson DA, Anderson JC, et al. American College of Gastroenterology guidelines for colorectal cancer screening 2009 [corrected]. Am J Gastroenterol 2009;104:739-50.

2. Leddin DJ, Enns R, Hilsden R, et al. Canadian Association of Gastroenterology position statement on screening individuals at average risk for developing colorectal cancer. Can J Gastroenterol 2010;24:705-14.

3. Rex DK, Petrini JL, Baron TH, et al. Quality indicators for colonoscopy. Gastrointest Endosc 2006;63:S16-28.

4. Freeman JL, Klabunde CN, Schussler N, et al. Measuring breast, colorectal, and prostate cancer screening with medicare claims data. Med Care 2002;40:IV-36-42.

5. Haque R, Chiu V, Mehta KR, et al. An automated data algorithm to distinguish screening and diagnostic colorectal cancer endoscopy exams. J Natl Cancer Inst Monogr 2005;35:116-8.

6. Schenck AP, Klabunde CN, Warren JL, et al. Data sources for measuring colorectal endoscopy use among Medicare enrollees. Cancer Epidemiol Biomarkers Prev 2007;16:2118-27.

7. Limoges-Gonzalez M, Mann NS, Al-Juburi A, et al. Comparisons of screening colonoscopy performed by a nurse practitioner and gastroenterologists: A single-center randomized controlled trial. Gastroenterol Nurs 2011;34:210-6.

8. Bair D, Pham J, Seaton MB, et al. The quality of screening colonoscopies in an office-based endoscopy clinic. Can J Gastroenterol 2009;23:41-7.

9. Soon MS, Kozarek RA, Ayub K, et al. Screening colonoscopy in Chinese and Western patients: A comparative study. Am J Gastroenterol 2005;100:2749-55.

10. Adler A, Roll S, Marowski B, et al. Appropriateness of colonoscopy in the era of colorectal cancer screening: A prospective, multicenter study in a private-practice setting (Berlin Colonoscopy Project 1, BECOP 1). Dis Colon Rectum 2007;50:1628-38. collected. However, polypectomy rate has been recently promoted as a more accessible quality measure compared with $\operatorname{ADR}(14,15)$. Thus, there is significance in our findings independent of ADR.

Strengths of our study include its multicentre design and involvment of more endoscopists than typically included in clinical studies of screening colonoscopy. Thus, our findings are less likely to be influenced by individual endoscopist or institution practices. In addition, we were able to adjust for the imperfect sensitivity and specificity of provincial health databases for polypectomy to obtain more accurate estimates (16).

\section{CONCLUSION}

The present study assessed the effect of different definitions of screening derived from patient and endoscopist perceptions on the computed polypectomy rate - a colonoscopy quality measure - in screening and nonscreening colonoscopies. Our findings suggest that despite considerable differences in the proportion of colonoscopies classified as screening, the various indications yielded very similar polypectomy rates. Polypectomy rates appear to be relatively insensitive to how screening is defined, which suggest that in research settings and for quality assurance programs, investigators and administrators have some flexibility in the way screening colonoscopy is defined.

INSTITUTIONS: This was a multicentre study involving hospitals of the McGill University Health Centre (Royal Victoria Hospital, Montreal General Hospital), St Mary's Hospital Center, Sir Mortimer B Davis Jewish General Hospital, Hôpital Maisonneuve-Rosemont, Hôpital Fleury, and Hôtel-Dieu.

GRANT SUPPORT: This research was funded by the Canadian Cancer Society and the Fonds de recherche du Québec-Santé (FRQS) through operating grants awarded to Maida Sewitch. Mengzhu Jiang was supported by the Canadian Institutes of Health Research through a Frederick Banting and Charles Best Canada Graduate Scholarship - Master's Award. Maida Sewitch is supported as a Chercheur Boursier Junior 2 of the FRQS. Alan Barkun is a Chercheur National of the FRSQ and holder of the Douglas G Kinnear Chair in Gastroenterology at McGill University.

11. Long MD, Martin C, Sandler RS, et al. Reduced polyp detection as endoscopy shift progresses: Experience with screening colonoscopy at a tertiary-care hospital. J Clin Gastroenterol 2011;45:253-8.

12. Sewitch MJ, Stein D, Joseph L, et al. Comparing patient and endoscopist perceptions of the colonoscopy indication. Can J Gastroenterol 2010;24:656-60.

13. Chen SC, Rex DK. Variable detection of nonadenomatous polyps by individual endoscopists at colonoscopy and correlation with adenoma detection. J Clin Gastroenterol 2008;42:704-7.

14. Francis DL, Rodriguez-Correa DT, Buchner A, et al. Application of a conversion factor to estimate the adenoma detection rate from the polyp detection rate. Gastrointest Endosc 2011;73:493-7.

15. Williams JE, Le TD, Faigel DO. Polypectomy rate as a quality measure for colonoscopy. Gastrointest Endosc 2010;73:498-506.

16. Wyse JM, Joseph L, Barkun AN, et al. Accuracy of administrative claims data for polypectomy. CMAJ 2011;183:E743-7.

17. Regula J, Rupinski M, Kraszewska E, et al. Colonoscopy in colorectal-cancer screening for detection of advanced neoplasia. N Engl J Med 2006;355:1863-72.

18. Schoenfeld P, Cash B, Flood A, et al. Colonoscopic screening of average-risk women for colorectal neoplasia. N Engl J Med 2005;352:2061-8.

19. Chen SC, Rex DK. Endoscopist can be more powerful than age and male gender in predicting adenoma detection at colonoscopy. Am J Gastroenterol 2007;102:856-61.

20. Rex DK. Colonoscopy: A review of its yield for cancers and adenomas by indication. Am J Gastroenterol 1995;90:353-65.

21. Fletcher RH, Nadel MR, Allen JI, et al. The quality of colonoscopy services - responsibilities of referring clinicians: A consensus statement of the Quality Assurance Task Group, National Colorectal Cancer Roundtable. J Gen Intern Med 2010;25:1230-4. 


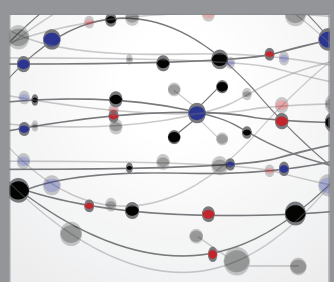

The Scientific World Journal
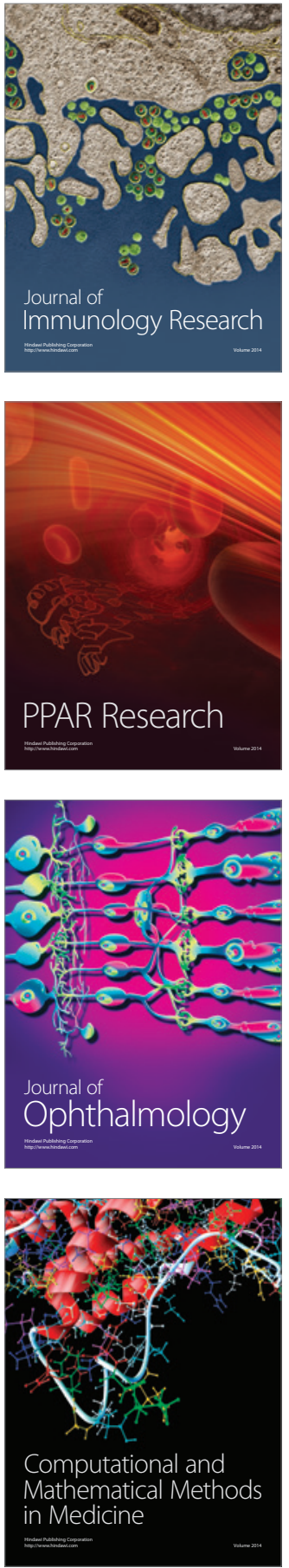

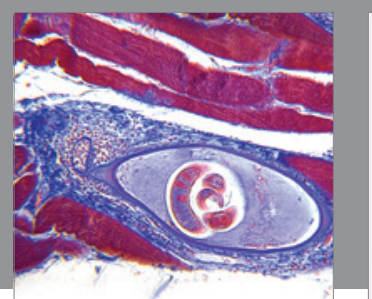

Gastroenterology Research and Practice

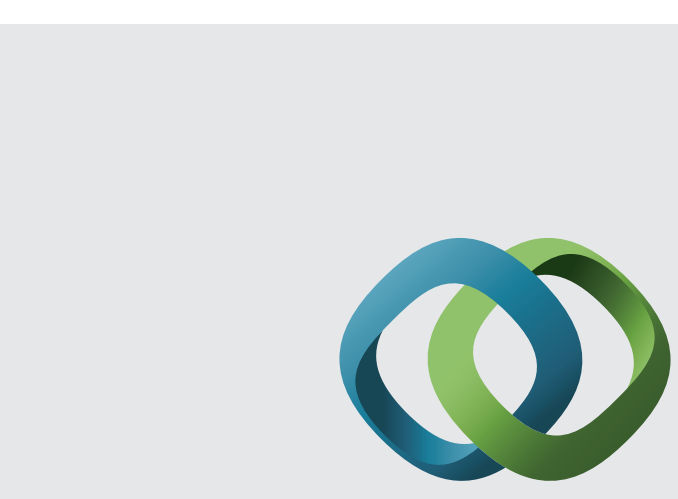

\section{Hindawi}

Submit your manuscripts at

http://www.hindawi.com
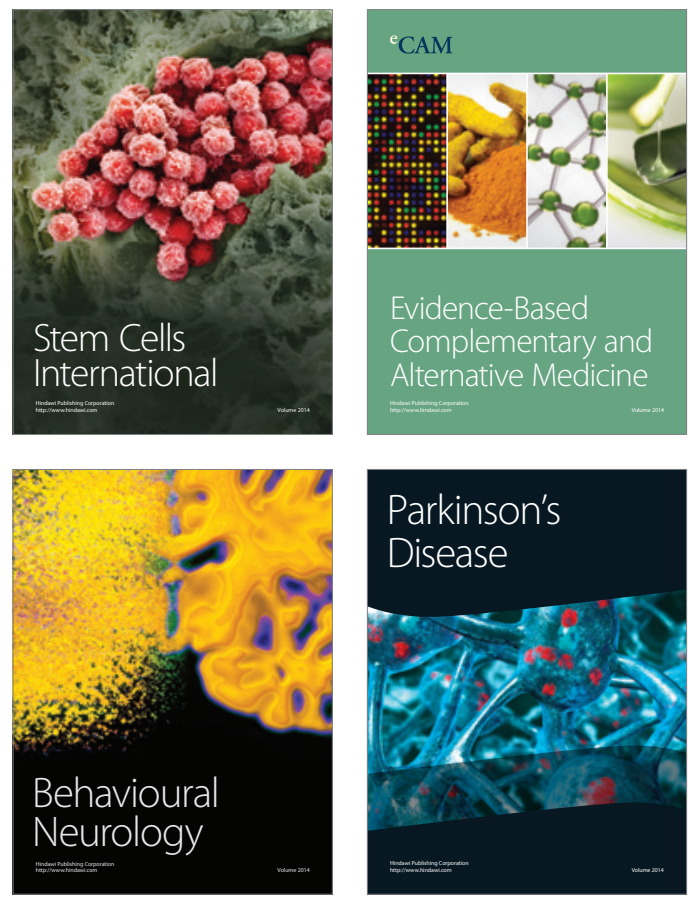
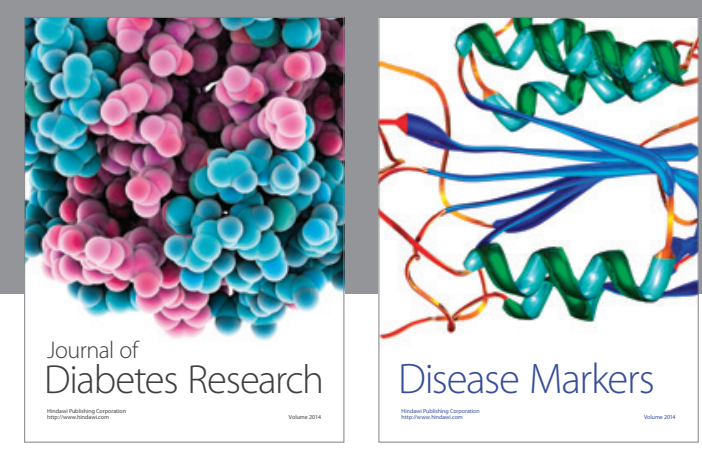

Disease Markers
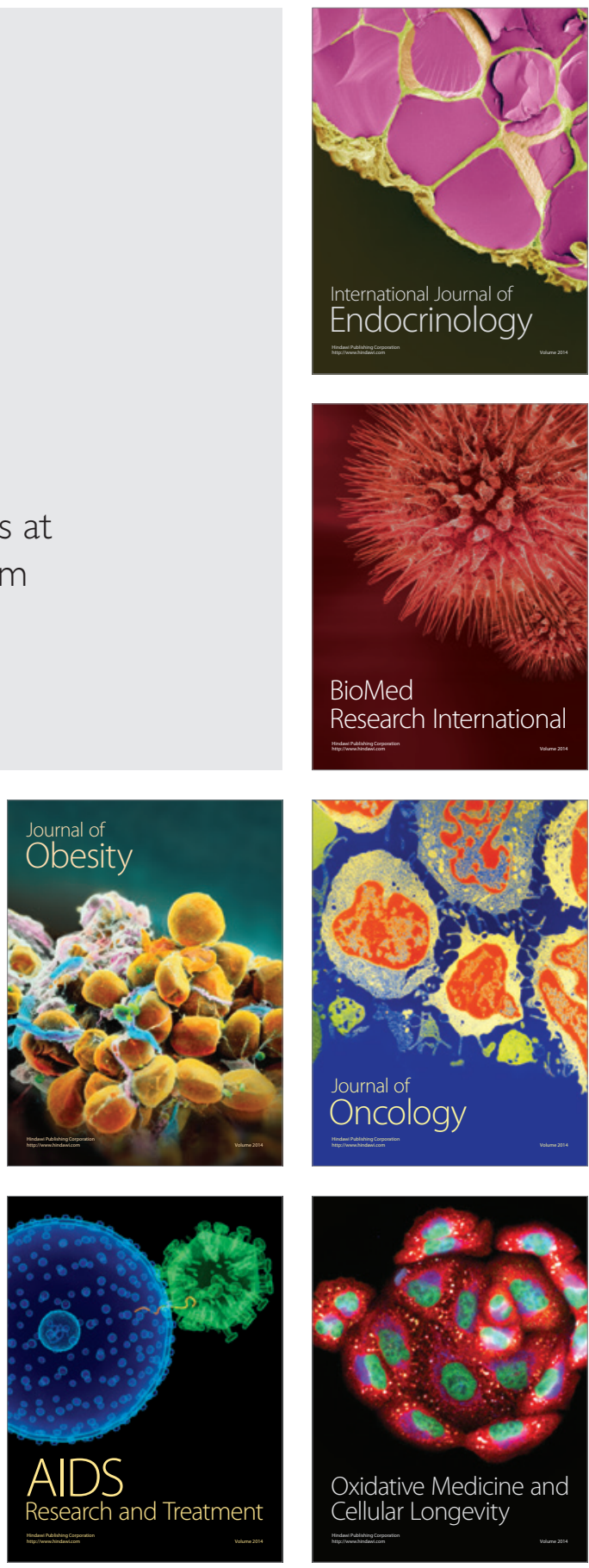